\title{
Erdheim-Chester Disease With Extensive Pericardial Involvement: A Case Report and Systematic Review
}

\author{
Alejandro Sanchez-Nadales ${ }^{\mathrm{a}, \mathrm{c}}$, Andrea Anampa-Guzman ${ }^{\mathrm{b}}$, Jessica Navarro-Motta ${ }^{\mathrm{a}}$
}

\begin{abstract}
Erdheim-Chester disease (ECD) is a rare non-Langerhans cell histiocytosis characterized by systemic xanthogranulomatous infiltration. We described the case of a female adult presenting with pericardial effusion. Pericardial infiltration is the most frequent cardiac manifestation of ECD and is the one discussed in this article. We found that the majority of patients with pericardial infiltration needed a cardiovascular procedure.
\end{abstract}

Keywords: ECD; Pericardial infiltration; BRAF mutation; Vemurafenib

\section{Introduction}

Erdheim-Chester disease (ECD) is a rare multisystem nonLangerhans cell histiocytosis characterized by systemic xanthogranulomatous infiltration from histiocytes $[1,2]$. This disease was first described by Erdheim and Chester in 1930 [3]. The number of cases reporting this disease is small (less than 600), but it has had dramatically increased in recent years, maybe by the increased diagnostic methods available, which enhances the recognition of the disease [4]. Patients with ECD commonly present in the fifth decade; however, pediatric and geriatric presentations have also been reported. ECD results from xanthogranulomatous infiltration of foamy histiocytes; these cells are positive for CD68, negative for CD1a, and in $80 \%$ of the cases negative for S100 [5]. ECD manifests as long bone infiltrations, exophthalmos, diabetes insipidus, xanthelasma, interstitial lung disease, bilateral adrenal infiltration, retroperitoneal fibrosis with perirenal or ureteral infiltration causing hydronephrosis and renal failure, testicular infiltration,

Manuscript submitted February 9, 2020, accepted February 26, 2020

aDepartment of Medicine, Advocate Illinois Masonic Medical Center, Chicago, IL, USA

bSociedad Cientifica de San Fernando, Faculty of Medicine, Universidad Nacional Mayor de San Marcos, Lima, Peru

${ }^{\mathrm{c} C}$ Corresponding Author: Alejandro Sanchez-Nadales, Department of Medicine, Advocate Illinois Masonic Medical Center, Chicago, IL, USA.

Email: alejandrosancheznadales@gmail.com

doi: https://doi.org/10.14740/cr1025 and in exceptional involves the hearth and the central nervous system [6].

The diagnosis of ECD is based on radiologic and histologic criteria. Imaging studies are prompted for the bone pain referred by the patients. X-rays show bilateral symmetric metaphyseal osteosclerosis of long bones. These lesions are considered virtually pathognomonic. The $99 \mathrm{mTc}$ Bone Scintigraphy shows symmetric and abnormally strong $99 \mathrm{mTc}$ labeling of the distal ends of the long bones. Microscopy of the lesions shows typical ECD histiocytes. These histiocytes are non-Langerhans' foamy histiocytes, which lack Birbeck granules, nested within a polymorphic granuloma, fibrosis or xanthogranulomatous. Pathological confirmation of $\mathrm{CD}^{+} 8^{+}$, $\mathrm{CD} 1 \mathrm{a}^{-}$histiocytes is both sufficient and mandatory for the diagnosis of ECD [6].

Specific somatic genetic mutations in the BRAF V600 gene have been reported in around $54 \%$ of patients suffering of ECD, rendering a therapeutic target for the kinase inhibitor, vemurafenib [7]. This medication is the only active Food and Drug Administration (FDA) approved treatment for ECD and has demonstrated long-term efficacy in patients with this genetic mutation [8]. Other medications, as dabrafenib (a BRAF $\mathrm{V} 600 \mathrm{E}$ inhibitor) and trametinib (a mitogen-activated protein kinase inhibitor), are under study as potential therapeutic options [9].

\section{Case Report}

We present the case of a 53-year-old woman with diabetes insipidus that has been treated with desmopressin for about 8 years, migraine with aura, and known ECD confirmed by biopsy, with possible involvement of the great cardiac vessel and infiltrative cardiomyopathy. Over the past several years, she has dealt with a multitude of intermittently exacerbated symptoms, including headaches, fatigue, lethargy, exertional dyspnea, flushing, and peripheral edema, which have been clinically attributed to mast cell activation. She was admitted twice during the previous year with symptoms of fluid retention that resolved with diuresis. She was diagnosed with ECD 2 months before this admission, with biopsy confirmation from the vertebra and the left femur. She was admitted to our institution for further management of a newly identified large pericardial effusion (Fig. 1) and ascites, accurately to assess the extension of the cardiac involvement by this disease. In the interim, she had complained of intermittent midsternal chest discomfort associated with dry cough and palpitations that worsened while 


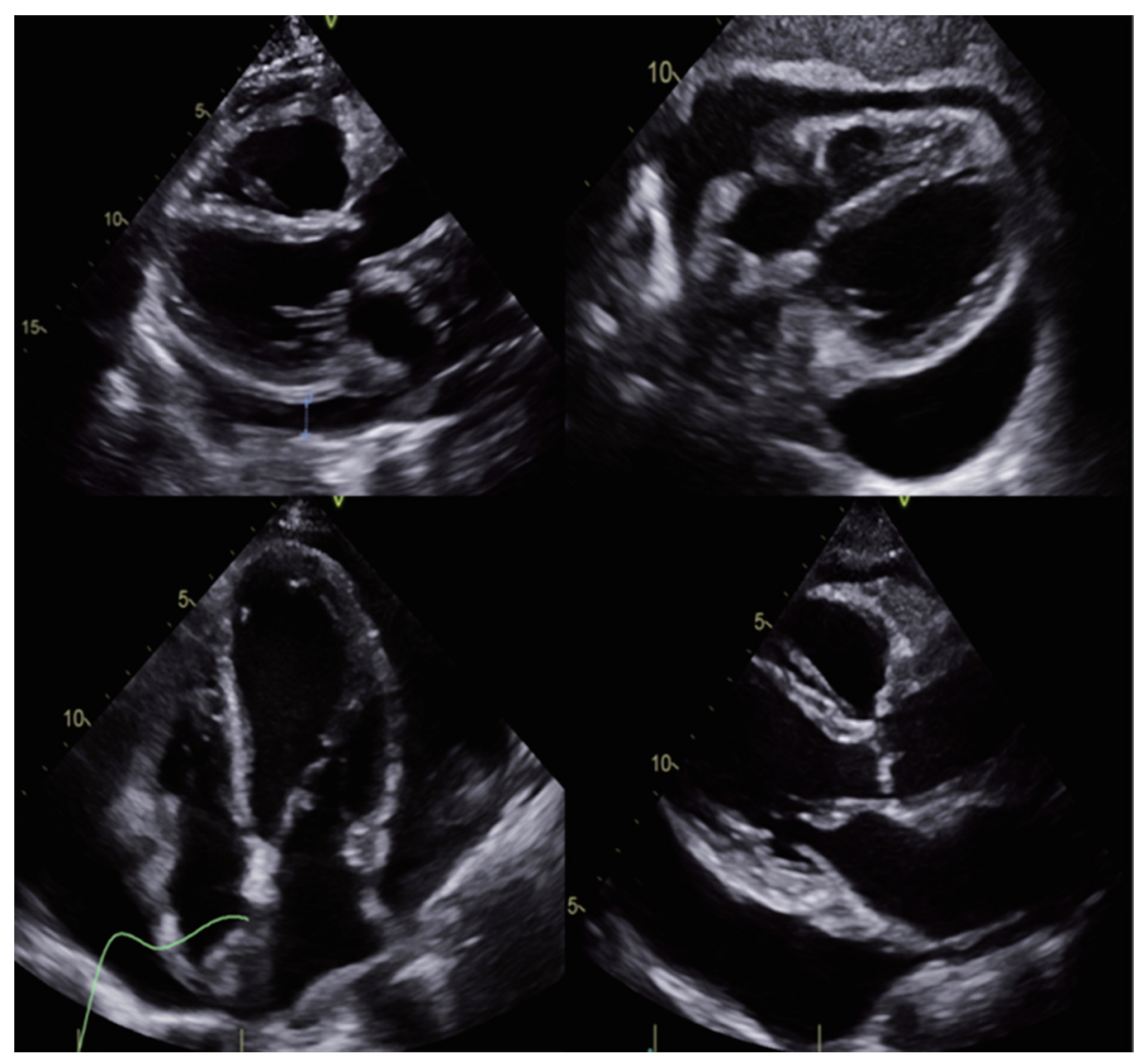

Figure 1. Large pericardial effusion.

lying flat.

She was found to have an acute right frontal infarct and multifocal stenosis through the vessel imaging modalities. A magnetic resonance imaging (MRI) showed infarction in the right frontal and parietal white matter, while the magnetic resonance angiography (MRA) revealed extensive intracranial stenosis in the anterior circulation. The final cerebral angiogram showed a right internal carotid artery occlusion, likely secondary to fibromuscular dysplasia changes (Fig. 2). Cerebrospinal fluid tests were normal, and the neurology service concluded that these changes were consistent with vasculopathy secondary to ECD with BRAF mutation.

Transesophageal echocardiography (TEE) showed a large circumferential pericardial effusion greater than $2 \mathrm{~cm}$ with maximum thickness around the inferior and posterior left ventricle wall with the partial systolic collapse of the right atrium. She had an ejection fraction of $69 \%$ and large pericardial effusion without tamponade physiology. After the evacuation of the pericardial effusion via video-assisted thoracoscopic surgery (VATS), there was minimal pericardial effusion remaining. The pathology exam from pericardium showed histiocytic infiltration compatible with ECD, positive for the BRAF mutation. From these findings, it was concluded that the patient was suffering from a vasculopathy related to ECD. She received corticosteroids for the treatment of the histiocytosis caused by ECD.

She continued her desmopressin for her diabetes insipi- dus, and she was started on daily aspirin and prednisone, along with pantoprazole and vitamin $\mathrm{D}$ for stomach and bone protection. A limited echocardiogram 8 days after VATS showed significant improvement in pericardial effusion (Fig. 3). She was discharged on colchicine, bumetanide and bactrim for prophylaxis against Pneumocystis jiroveci pneumonia. Before going home, a cardiac MRI was done to record the extension of the disease and help with future monitoring (Fig. 4). It was planned to start vemurafenib due to the discovery of the BRAF mutation.

\section{Methods}

The process developed for the literature review included the following steps.

First, the relevant keywords were established. We conducted a broad search using the terms pericardial effusion and ECD.

Second, Scopus, PubMed, EMBASE, and Cochrane were searched for published articles through September 2019. The combinations of the terms used were: 1) SCOPUS, TITLEABS-KEY ("Erdheim-Chester Disease") AND TITLE-ABSKEY ("Pericardial Effusion"); 2) PUBMED, "Erdheim-Chester Disease" (Mesh) AND "Pericardial Effusion" (Mesh); 3) EMBASE, TITLE-ABS-KEY ("Erdheim-Chester Disease") AND TITLE-ABS-KEY ("Pericardial Effusion"); and 4) 


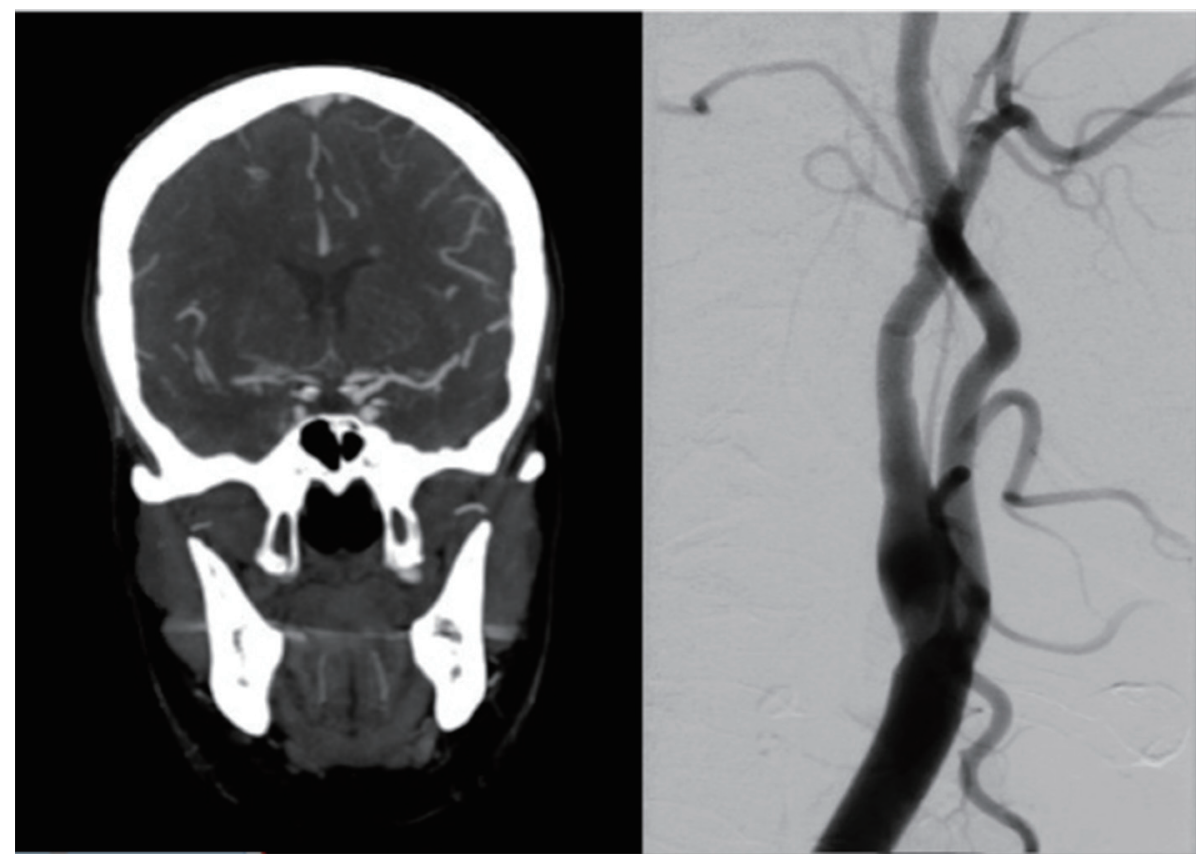

Figure 2. Right internal carotid artery occlusion.

COCHRANE, "Erdheim-Chester Disease" in Title Abstract Keyword AND "Pericardial Effusion" in Title Abstract Keyword (word variations have been searched). A total of 206 articles were found ( 84 from Scopus, 15 from PubMed, 107 from EMBASE and no articles found in Cochrane).

Third, article abstracts were reviewed for study eligibility, followed by reviews of full papers in cases in which eligibility was not clear from the abstract review alone. Another 18 full-text articles were excluded. Figure 5 shows the flow diagram according to the Preferred Reporting Items for Systematic Reviews and Meta-Analyses (PRISMA) statement [7].

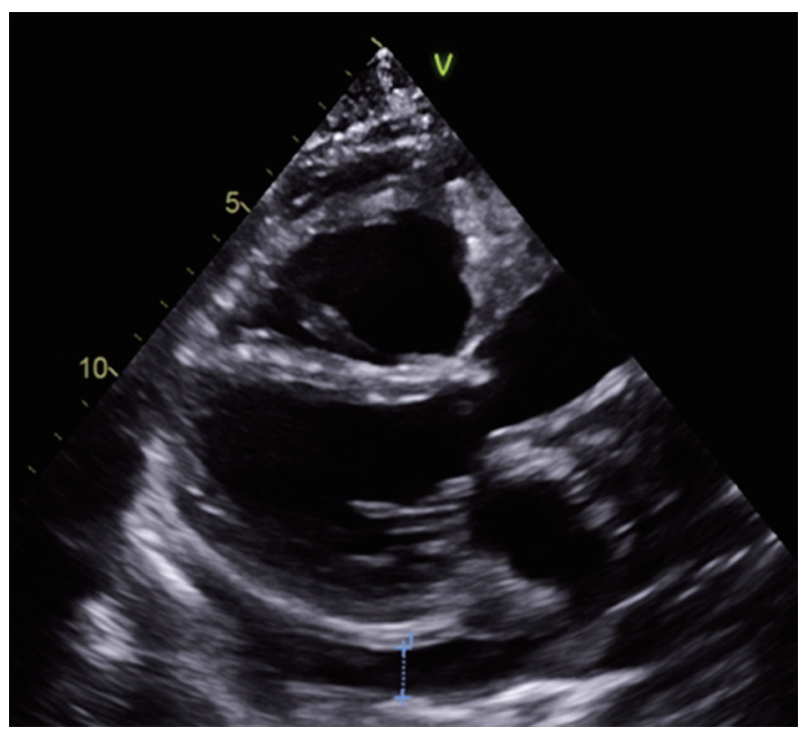

Figure 3. Reduction in pericardial effusion compared to Figure 1.

\section{Selection of studies}

Articles were included if they consisted of presentation of pericardial effusion and ECD. Articles were excluded if they were primarily editorials, and solely described study protocols, letters, abstract of congresses or books. The results were summarized in tables.

\section{Results}

Fifty-two articles were included in the analysis. Table 1 shows the main characteristics of them. Most of the studies were case reports, eight were reviews and only three were original articles. Table 2 shows the case reports and case series in which patients with ECD presented with pericardial effusion [10-41]. The average age of the patients with ECD who presented with pericardial effusion was $56.64 \pm 10.5$. The majority of them were men $(54.29 \%)$. Table 3 shows the interventions in patients reviewed. Almost $40 \%$ of the patients reviewed did not need any cardiologic procedure. A total of $30.3 \%$ of the patients received pericardiocentesis. Four received pleuro-pericardial window; three, pericardial window and two, pericardiectomy. The following procedures were performed in only one patient: mediastinoscopy, pericardial drainage, and sternotomy. One patient had pericardiocentesis and later received pericardiectomy, and another had pericardiocentesis done twice and later a pleuro-cardial window.

\section{Discussion}

Approximately $75 \%$ of patients with ECD suffer cardiovas- 


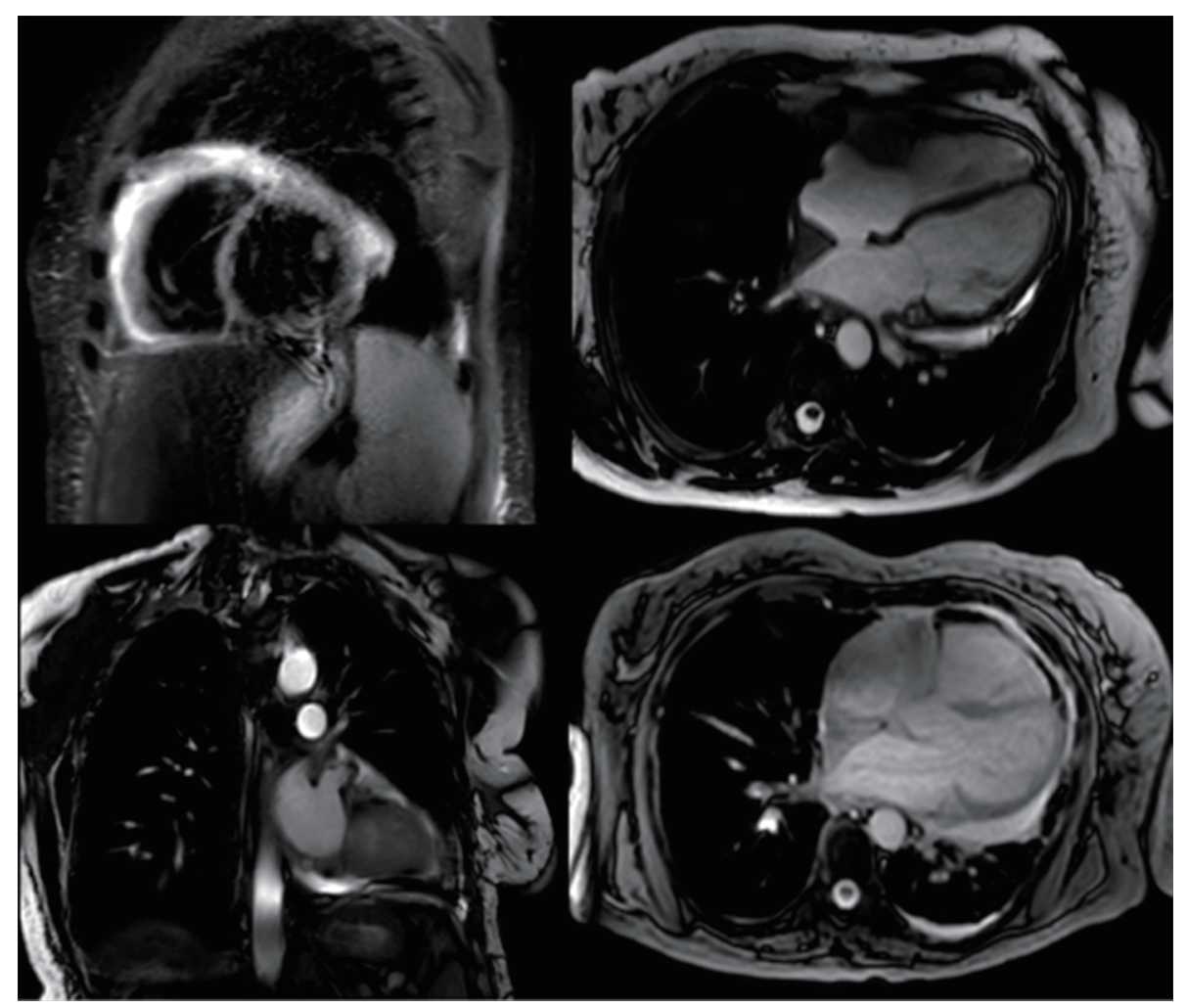

Figure 4. Cardiac MRI with very scarce effusion. MRI: magnetic resonance imaging.

cular manifestations and about $60 \%$ of them will perish due to cardiac complications [10]. Patients with ECD and cardiac involvement have a reduced response to treatment and a poor overall prognosis [42]. There are several types of cardiac injuries that can cause congestive heart failure, including myocardial infarction, thromboembolism, cardiac remodeling, valve dysfunction, ischemia, and peripheral edema among others. Pericardial infiltration is the most frequent cardiac manifestation of ECD [43] and is the one discussed in this article.

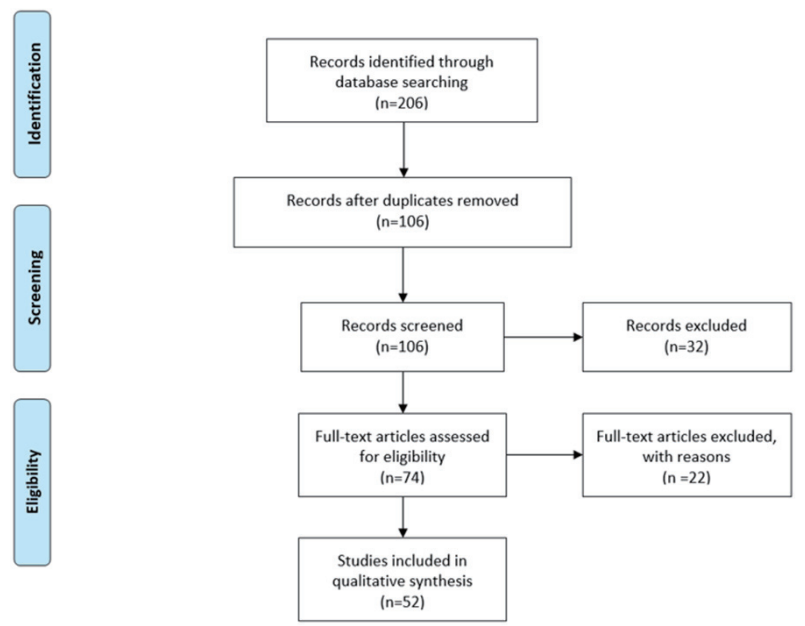

Figure 5. Flow diagram according to the PRISMA statement. PRISMA: Preferred Reporting Items for Systematic Reviews and Meta-Analyses.
Pericardial involvement in ECD takes several forms and the symptoms are correlated with type, extent, and severity. Pericardial infiltration is easily discovered with computed tomography and transthoracic echocardiography. The pericardium may appear thickened with or without a fibrosis wrap. The accumulation of pericardial effusion can lead to cardiac tamponade. This can be relieved with pericardiocentesis, which has diagnostic and therapeutic purposes. Aggressive interventions may include placement of a pericardial window, pericardiectomy, and placement of a pericardial-abdominal shunt. Cytological examination of pericardial effusion can reveal mesothelial cells, histiocytes, and inflammatory cells. A histological examination of a pericardial sample may reveal the infiltration of foamy histiocytes [44]. In our revision, we found that the majority of the patients with pericardial infiltration needed a cardiovascular procedure. Pericardial infiltration can manifest as pericardial thickening and symptoms vary according to the degree of disease severity. Myocardial involvement occurs sequentially to the pericardial involvement and manifests as myocardial hypertrophy, easily diagnosed by the echocardiogram. Thickening can be found in the ventricles, atria, coronary sulci and interatrial septum [11].

To date, several treatments have been administered to patients with ECD in an attempt to achieve remission or at least stabilization. Currently, interferon- $\alpha$ provides the best management strategy, with a sustainable stabilization of the disease in most cases [45-48]. Interferon- $\alpha$ is administered in doses that vary from three million units three times per week to nine million units three times per week. Peginterferon- $\alpha-2 a$, 
Table 1. Characteristics of Articles

\begin{tabular}{|c|c|c|}
\hline Characteristic & $\mathbf{N}$ & $\%$ \\
\hline \multicolumn{3}{|l|}{ Type of article } \\
\hline Case report & 28 & $53.85 \%$ \\
\hline Review & 8 & $15.38 \%$ \\
\hline Letter & 4 & $7.69 \%$ \\
\hline Series of cases & 4 & $7.69 \%$ \\
\hline Original & 3 & $5.77 \%$ \\
\hline Other small publications & 5 & $9.62 \%$ \\
\hline \multicolumn{3}{|l|}{ Year } \\
\hline 2001 & 1 & $1.92 \%$ \\
\hline 2003 & 1 & $1.92 \%$ \\
\hline 2004 & 1 & $1.92 \%$ \\
\hline 2006 & 2 & $3.85 \%$ \\
\hline 2007 & 1 & $1.92 \%$ \\
\hline 2010 & 3 & $5.77 \%$ \\
\hline 2011 & 3 & $5.77 \%$ \\
\hline 2012 & 3 & $5.77 \%$ \\
\hline 2013 & 2 & $3.85 \%$ \\
\hline 2014 & 5 & $9.62 \%$ \\
\hline 2015 & 6 & $11.54 \%$ \\
\hline 2016 & 8 & $15.38 \%$ \\
\hline 2017 & 6 & $11.54 \%$ \\
\hline 2018 & 8 & $15.38 \%$ \\
\hline 2019 & 2 & $3.85 \%$ \\
\hline
\end{tabular}

the pegylated form of interferon- $\alpha$, is an equivalent alternative to interferon- $\alpha$. It is administered in doses that vary from 135 to $200 \mu \mathrm{g}$ per week [45]. It should be noted that treatment with these agents is prolonged. Therefore, treatment tolerance should be considered fundamental in long-term treatment planning. Among the adverse effects of interferon- $\alpha$ are asthenia, myalgia, pruritus, thrombocytopenia, and depression [49].

The efficacy of interferon- $\alpha$ varies according to the different sites of disease involvement. A recent survey involving 24 patients treated with high doses of interferon- $\alpha(>18$ million units per week) or high doses of peginterferon- $\alpha-2 \mathrm{a}(>185 \mu \mathrm{g}$ per week) reported that they were effective in treating patients with severe ECD. The response to treatment was most prominent in the cutaneous foci of the disease, followed by foci in the central nervous system (CNS) and pituitary; foci of the lung and heart were more resistant to treatment [49]. Interferon- $\alpha$ treatment itself was identified as an independent predictor of survival. It is currently the only agent that has been shown to improve survival among patients with ECD. Cladribine is recommended as an alternative treatment for ECD. However, the literature contains significantly fewer data regarding this medication compared to interferon- $\alpha$ [45].

In the past, vemurafenib proved to be an effective therapeutic option in patients with melanoma-BRAF V600 muta- tion; the reason why this medication was tested in patients with ECD was a link found between this disease and a specific BRAF V600 mutation. A nonrandomized, open-label phase 2 clinical trial by Diamond et al showed long-term efficacy in patients with BRAF V600-mutant ECD [8]. Vemurafenib gained FDA approval in 2017 with an oral dose of $960 \mathrm{mg}$ every $12 \mathrm{~h}$. Common side effects include arthralgia, alopecia, maculopapular rash, fatigue, photosensitivity, uveitis, and prolonged QT interval. Skin cancer, anaphylaxis, drug reaction with eosinophilia and systemic symptoms (DRESS) syndrome, Stevens-Johnson syndrome, toxic epidermal necrolysis, hepatotoxicity, kidney failure, Dupuytren's contracture and teratogenicity have been described as rare but severe side effects.

\section{Conclusions}

ECD is a rare non-Langerhans cell histiocytosis characterized by systemic xanthogranulomatous infiltration. We described the case of a female adult presenting with pericardial effusion. Pericardial infiltration is the most frequent cardiac manifestation of ECD and is the one discussed in this article. We found that the majority of the patients with pericardial infiltration needed a cardiovascular procedure.

\section{Acknowledgments}

We would like to express our sincere thanks to Mr. Breandan Richard Quinn for his help and assistance in the editing and proofreading of this article.

\section{Financial Disclosure}

This project was not supported by any grant or funding agencies.

\section{Conflict of Interest}

The authors declare that they have no competing interest.

\section{Informed Consent}

It was determined that informed consent was not necessary because data was obtained from medical records and anonymized.

\section{Author Contributions}

All authors contributed to manuscript writing and approved the final version. ASN, AAG, and JNM contributed to conception and design and data analysis and interpretation. AAG contributed to the collection and assembly of data and design and data analysis and interpretation. ASN, AAG, and JNM helped 


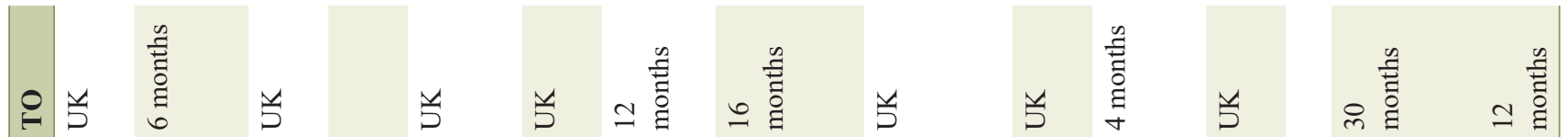

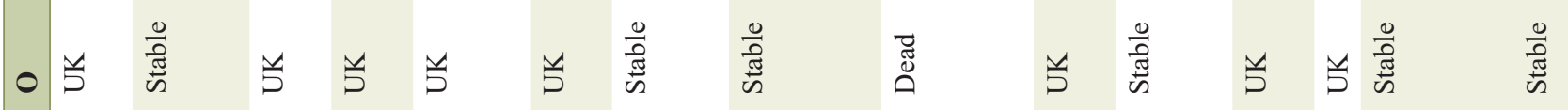

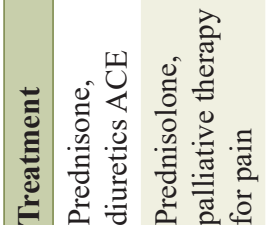

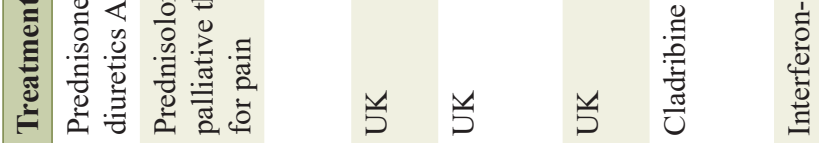

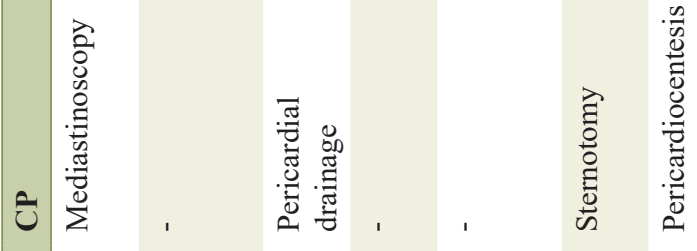

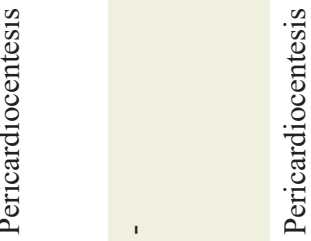

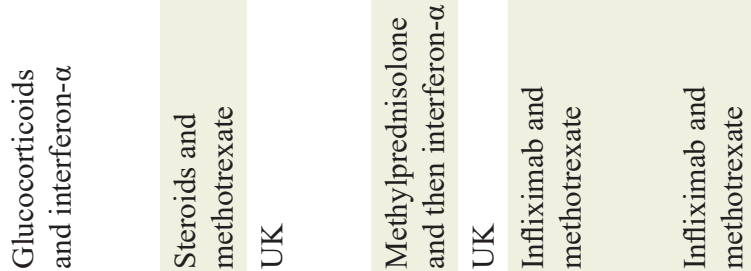

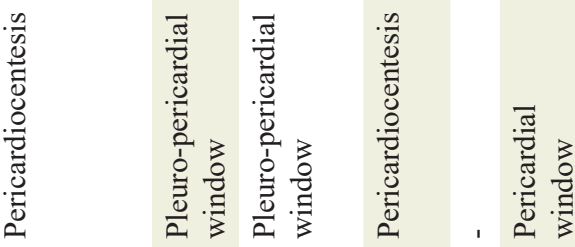

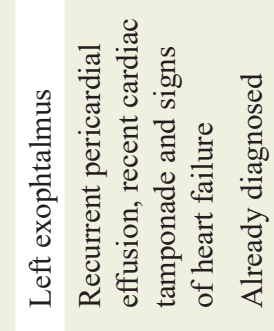

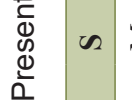

in $\sin$

$\infty$

6

$\therefore$ in

in

응

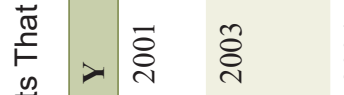

¿্ণ

๕ั ๕

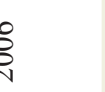

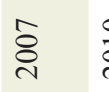

$\stackrel{\circ}{\circ}$

$\stackrel{ }{\stackrel{2}{2}}$

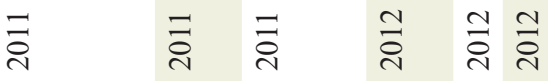

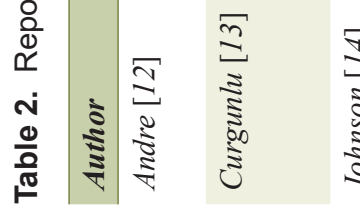

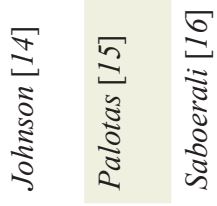

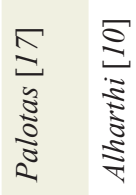

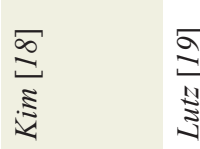

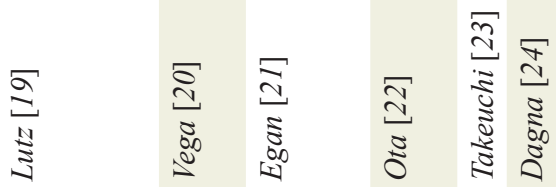


의

○.

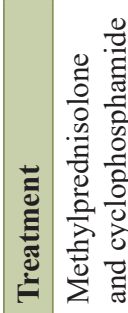

善善高

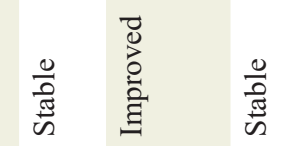

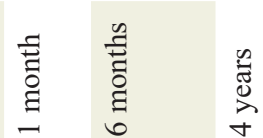

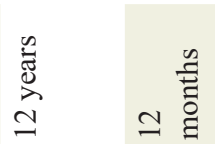

㩊咅

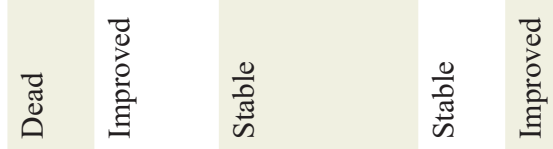

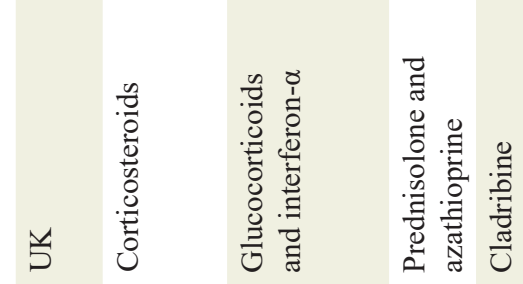

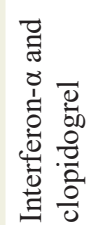
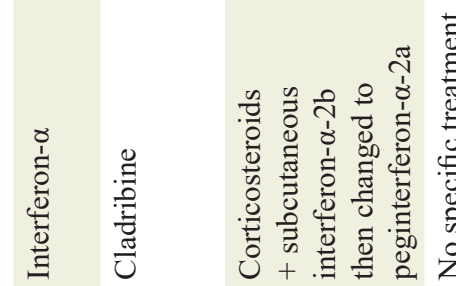

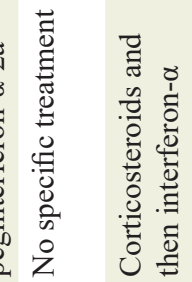
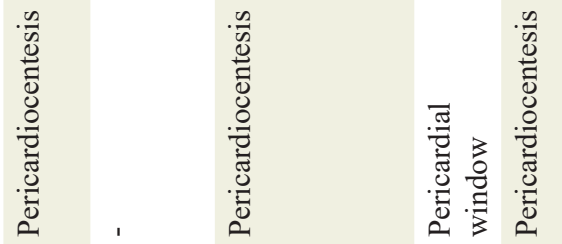
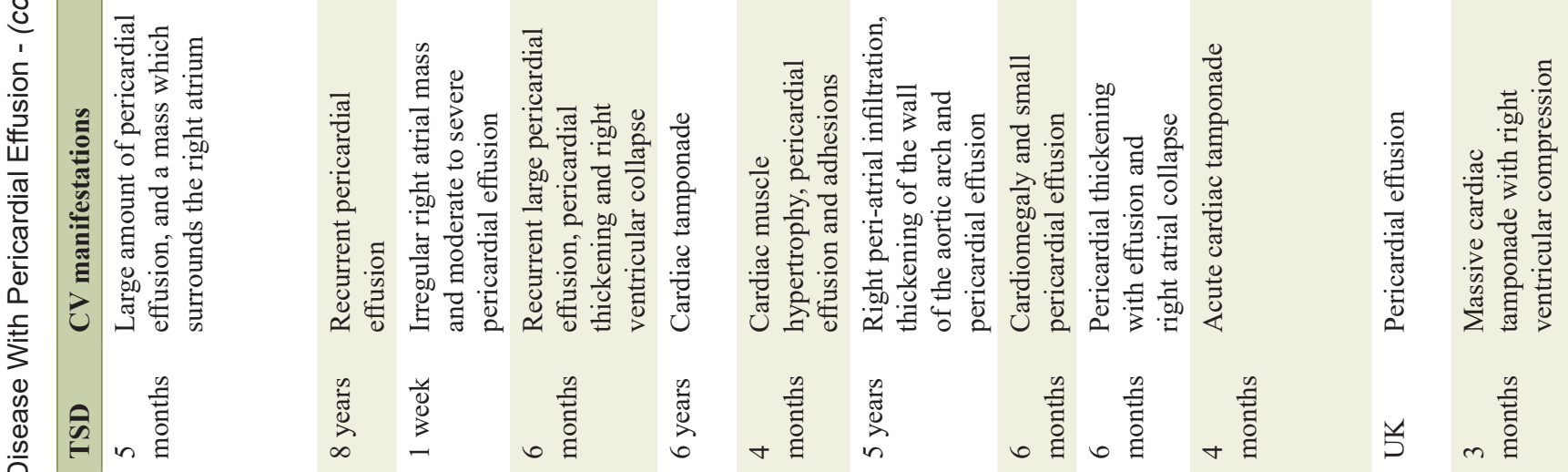

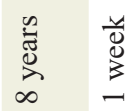

๑

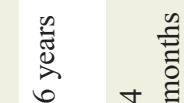

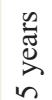

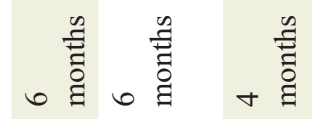

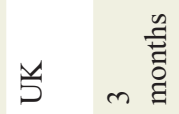

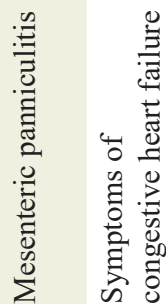

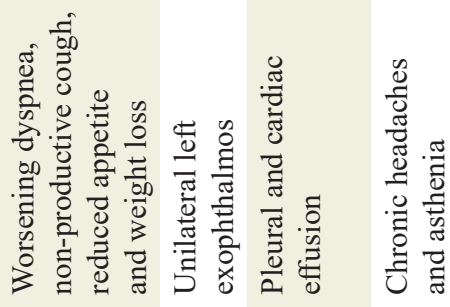

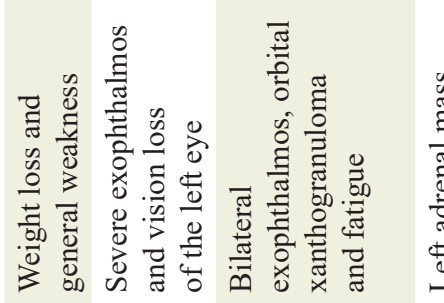

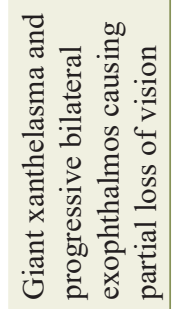

in $\overline{6}$ in

$\rightarrow 5$ in

$\infty \pi$

₹

$\Sigma \Sigma$

山

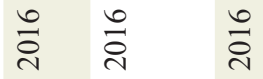

จั่

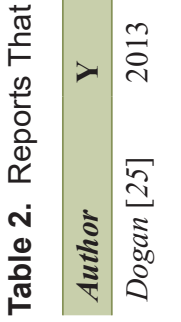

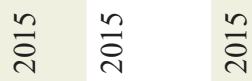

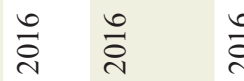

ำ

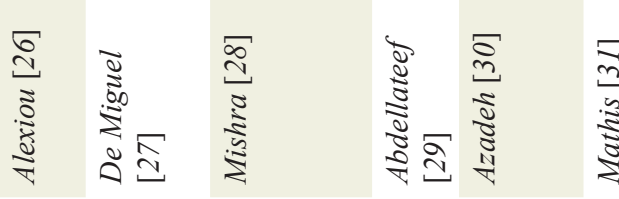

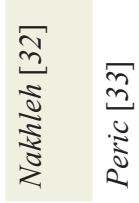

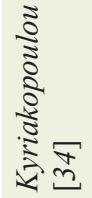

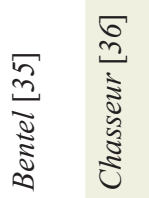




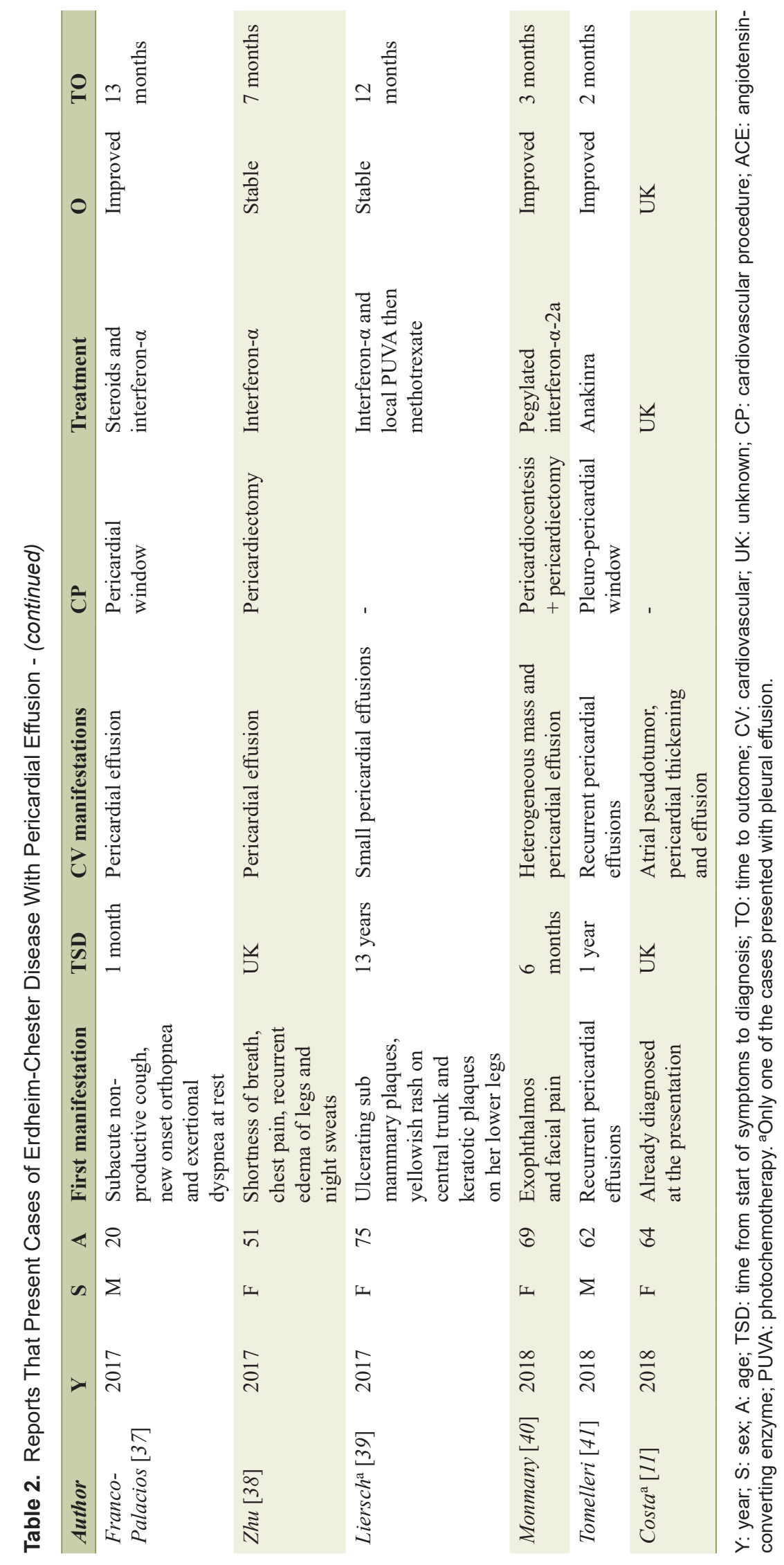


Table 3. Interventions Performed in the Cases of Erdheim-Chester Disease With Pericardial Effusion

\begin{tabular}{lll}
\hline Procedure & $\mathbf{N}$ & $\%$ \\
\hline None & 13 & $39.39 \%$ \\
Pericardiocentesis & 8 & $24.24 \%$ \\
Pericardial window & 3 & $9.09 \%$ \\
Pleuro-pericardial window & 3 & $9.09 \%$ \\
Mediastinoscopy & 1 & $3.03 \%$ \\
Pericardectomy & 1 & $3.03 \%$ \\
Pericardial drainage & 1 & $3.03 \%$ \\
Sternotomy & 1 & $3.03 \%$ \\
Pericardiocentesis + pericardectomy & 1 & $3.03 \%$ \\
Pericardiocentesis + pericardiocentesis + pleuro-pericardial window & 1 & $3.03 \%$ \\
\hline
\end{tabular}

with data analysis and interpretation. All authors read and approved the final manuscript.

\section{Data Availability}

The data supporting the findings of this study are available from the corresponding author upon reasonable request.

\section{References}

1. Unal E, Karcaaltincaba M, Akpinar E, Ariyurek OM. The imaging appearances of various pericardial disorders. Insights Imaging [Internet]. 2019;10(1):42.

2. Nicolazzi MA, Carnicelli A, Fuorlo M, Favuzzi AMR, Landolfi R. Cardiovascular involvement in ErdheimChester disease. Medicine (Baltimore) [Internet]. 2015;94(43):e1365.

3. Chester W. Lipoidgranulomatose. Virchows Arch Pathol Anat. 1930;279:561-602.

4. Consensus guidelines for the diagnosis and clinical management of Erdheim-Chester disease. Blood Journal [Internet]. Available from: http://www.bloodjournal.org/ content/early/2014/05/21/blood-2014-03-561381/tabarticle-info.

5. Maladie d'Erdheim-Chester - ScienceDirect [Internet]. Available from: https:/www.sciencedirect.com/science/ article/pii/S0248866314004755.

6. Mazor RD, Manevich-Mazor M, Shoenfeld Y. ErdheimChester Disease: a comprehensive review of the literature. Orphanet J Rare Dis. 2013;8:137.

7. Haroche J, Charlotte F, Arnaud L, von Deimling A, Helias-Rodzewicz Z, Hervier B, Cohen-Aubart F, et al. High prevalence of BRAF V600E mutations in Erdheim-Chester disease but not in other non-Langerhans cell histiocytoses. Blood. 2012;120(13):2700-2703.

8. Diamond EL, Subbiah V, Lockhart AC, Blay JY, Puzanov I, Chau I, Raje NS, et al. Vemurafenib for BRAF V600mutant Erdheim-Chester disease and langerhans cell histiocytosis: analysis of data from the histology-inde- pendent, phase 2, Open-label VE-BASKET study. JAMA Oncol. 2018;4(3):384-388.

9. Al Bayati A, Plate T, Al Bayati M, Yan Y, Lavi ES, Rosenblatt JD. Dabrafenib and trametinib treatment for Erdheim-Chester disease with brain stem involvement. Mayo Clin Proc Innov Qual Outcomes. 2018;2(3):303-308.

10. Alharthi MS, Calleja A, Panse P, Appleton C, Jaroszewski DE, Tazelaar HD, Mookadam F. Multimodality imaging showing complete cardiovascular involvement by Erdheim-Chester disease. Eur J Echocardiogr. 2010;11(7):E25.

11. Costa I, Abdo ANR, Bittar CS, Fonseca SMR, Moraes A, Kalil Filho R, Pereira J, et al. Cardiovascular manifestations of Erdheim-Chester's disease: a case series. Arq Bras Cardiol. 2018;111(6):852-855.

12. Andre M, Delevaux I, de Fraissinette B, Ponsonnaille J, Costes Chalret N, Wechsler B, Piette JC, et al. Two enlarged kidneys: a manifestation of Erdheim-Chester disease. Am J Nephrol. 2001;21(4):315-317.

13. Curgunlu A, Karter Y, Ozturk A. Erdheim-Chester disease: a rare cause of paraplegia. Eur J Intern Med. 2003;14(1):53-55.

14. Johnson MD, Aulino JP, Jagasia M, Mawn LA. Erdheimchester disease mimicking multiple meningiomas syndrome. AJNR Am J Neuroradiol. 2004;25(1):134-137.

15. Palotas A, Bogats G, Lazar M, Papos M, Matin K, Pavics L. An isotope-diagnostic approach to Erdheim-Chester's disease of the heart. J Cardiovasc Pharmacol Ther. 2006;11(4):274-279.

16. Saboerali MD, Koolen MG, Noorduyn LA, van Delden OM, Bogaard HJ. Pleural thickening in a construction worker: it is not always mesothelioma. Neth J Med. 2006;64(3):88-90.

17. Palotas A, Bogats G, Lazar M, Papos M, Matin K, Pavics L. Radiopharmaceutical diagnosis of Erdheim-Chester's disease. Nucl Med Commun. 2007;28(1):63-65.

18. Kim MS, Kim $\mathrm{CH}$, Choi SJ, Won $\mathrm{CH}$, Chang SE, Lee MW, Choi JH, et al. Erdheim-chester disease. Ann Dermatol. 2010;22(4):439-443.

19. Lutz SZ, Schmalzing M, Vogel-Claussen J, Adam P, May AE. [Recurrent pericardial effusion as first manifestation 
of Erdheim-Chester disease]. Dtsch Med Wochenschr. 2011;136(39):1952-1956.

20. Vega J, Cisternas M, Bergoeing M, Espinosa R, Zapico A, Chadid P, Santamarina M. [Erdhei-Chester disease: report of one case]. Rev Med Chil. 2011;139(8):1054-1059.

21. Egan A, Sorajja D, Jaroszewski D, Mookadam F. Erdheim-Chester disease: The role of video-assisted thoracoscopic surgery in diagnosing and treating cardiac involvement. Int J Surg Case Rep. 2012;3(3):107-110.

22. Ota M, Sakamoto M, Sato K, Yoshida Y, Funakubo Asanuma Y, Akiyama Y, Yamakawa M, et al. Immunopathological analysis of Erdheim-Chester disease with massive ascites. Intern Med. 2012;51(19):2825-2830.

23. Takeuchi T, Sato M, Sonomura T, Itakura T. ErdheimChester disease associated with intramedullary spinal cord lesion. Br J Radiol. 2012;85(1011):e62-64.

24. Dagna L, Corti A, Langheim S, Guglielmi B, Cobelli FD, Doglioni $\mathrm{C}$, et al. Tumor necrosis factor $\alpha$ as a master regulator of inflammation in Erdheim-Chester disease: rationale for the treatment of patients with infliximab. J Clin Oncol. 2012;(28):e286-e290.

25. Dogan R, Aydin A, Temel H, Ozer N, Onder S, Hazırolan T, et al. Erdheim-Chester disease with cardiac involvement: a new case report. Turk Gogus Kalp Dama. 2013;21:127-132.

26. Alexiou J, Klastersky J. Erdheim-Chester disease: a case report. Am J Case Rep. 2015;16:361-366.

27. de Miguel Criado J, Aguilera Del Hoyo LF, Garcia Del Salto L, Cueva Perez E, Casado Cerrada J, Nieto Llanos S, Porro Fernandez JC, et al. Case 224: Cardiac involvement in Erdheim-Chester disease. Radiology. 2015;277(3):916-921.

28. Mishra AK, Mani S, George AA, Sudarsanam TD. Recurrent pericardial effusion and tamponade in a patient with Erdheim-Chester disease (ECD). BMJ Case Rep. 2015;2015:bcr2015212483.

29. Abdellateef EE, Abdelhai AR, Gawish HH, Abdulmonaem GA, Abdelbary EH, Ahmed AI. The first reported case of Erdheim-Chester disease in Egypt with bilateral exophthalmos, loss of vision, and multi-organ involvement in a young woman. Am J Case Rep. 2016;17:360370 .

30. Azadeh N, Tazelaar HD, Gotway MB, Mookadam F, Fonseca R. Erdheim Chester Disease treated successfully with cladribine. Respir Med Case Rep. 2016;18:37-40.

31. Mathis S, Godeneche G, Haroche J, Milin S, Julian A, Berthomet A, Baron C, et al. Long-term outcome of basilar stenosis in Erdheim-Chester disease: A case report. Medicine (Baltimore). 2016;95(36):e4813.

32. Nakhleh A, Slobodin G, Elias N, Bejar J, Odeh M. Rapid progression to cardiac tamponade in Erdheim-Chester disease despite treatment with interferon alpha. Mod Rheumatol. 2016;26(4):621-624.

33. Peric P, Antic B, Knezevic-Usaj S, Radic-Tasic O, Radovinovic-Tasic S, Vasic-Vilic J, Sekulovic L, et al. Successful treatment with cladribine of Erdheim-Chester disease with orbital and central nervous system involvement developing after treatment of Langerhans cell histiocytosis. Vojnosanit Pregl. 2016;73(1):83-87.
34. Kyriakopoulou M, Decaux G, El Mourad M, Casado-Arroyo R. Acute cardiac tamponade in a 77-year-old italian woman with Erdheim-Chester disease. Eur J Case Rep Intern Med. 2016;3(7):000451.

35. Bentel JM, Thomas MA, Rodgers JJ, Arooj M, Gray E, Allcock R, Fermoyle S, et al. Erdheim-Chester disease associated with a novel, complex BRAF p.Thr599 Val600delinsArgGlu mutation. BMJ Case Rep. 2017;2017:bcr-2017-219720.

36. Chasseur P, Kyriakopoulou M, Vokaer B, Beukinga I, Casado Arroyo R, Cogan E, Couturier B. A cytologic diagnosis of BRAF(V600E) Erdheim-Chester disease on pericardial fluid. Acta Clin Belg. 2017;72(5):369-371.

37. Franco-Palacios D, McDonald A, Aguillard RN, Berry A. An unusual case of interstitial lung disease in a patient with cardiopulmonary syndrome as the initial presentation of Erdheim-Chester disease. BMJ Case Rep. 2017;2017:bcr-2017-220659.

38. Zhu P, Li N, Yu L, Miranda MN, Wang G, Duan Y. Erdheim-Chester disease with emperipolesis: a unique case involving the heart. Cancer Res Treat. 2017;49(2):553558.

39. Liersch J, Carlson JA, Schaller J. Histopathological and clinical findings in cutaneous manifestation of erdheimchester disease and langerhans cell histiocytosis overlap syndrome associated with the BRAFV600E mutation. Am J Dermatopathol. 2017;39(7):493-503.

40. Monmany J, Granell E, Lopez L, Domingo P. Resolved heart tamponade and controlled exophthalmos, facial pain and diabetes insipidus due to Erdheim-Chester disease. BMJ Case Rep. 2018;2018:bcr-2018-225224.

41. Tomelleri A, Cavalli G, De Luca G, Campochiaro C, D'Aliberti T, Tresoldi M, Dagna L. Treating heart inflammation with interleukin-1 blockade in a case of ErdheimChester disease. Front Immunol. 2018;9:1233.

42. Haroche J, Amoura Z, Charlotte F, Salvatierra J, Wechsler $\mathrm{B}$, Graux C, Brousse N, et al. Imatinib mesylate for platelet-derived growth factor receptor-beta-positive ErdheimChester histiocytosis. Blood. 2008;111(11):5413-5415.

43. Gupta A, Kelly B, McGuigan JE. Erdheim-Chester disease with prominent pericardial involvement: clinical, radiologic, and histologic findings. Am J Med Sci. 2002;324(2):96-100.

44. Haroche J, Amoura Z, Dion E, Wechsler B, CostedoatChalumeau N, Cacoub P, Isnard R, et al. Cardiovascular involvement, an overlooked feature of Erdheim-Chester disease: report of 6 new cases and a literature review. Medicine (Baltimore). 2004;83(6):371-392.

45. Arnaud L, Hervier B, Neel A, Hamidou MA, Kahn JE, Wechsler B, Perez-Pastor G, et al. CNS involvement and treatment with interferon-alpha are independent prognostic factors in Erdheim-Chester disease: a multicenter survival analysis of 53 patients. Blood. 2011;117(10):27782782.

46. Haroche J, Amoura Z, Trad SG, Wechsler B, Cluzel P, Grenier PA, Piette JC. Variability in the efficacy of interferon-alpha in Erdheim-Chester disease by patient and site of involvement: results in eight patients. Arthritis Rheum. 2006;54(10):3330-3336. 
47. Braiteh F, Boxrud C, Esmaeli B, Kurzrock R. Successful treatment of Erdheim-Chester disease, a non-Langerhans-cell histiocytosis, with interferon-alpha. Blood. 2005;106(9):2992-2994.

48. Suzuki HI, Hosoya N, Miyagawa K, Ota S, Nakashima H, Makita N, Kurokawa M. Erdheim-Chester disease: mul- tisystem involvement and management with interferonalpha. Leuk Res. 2010;34(1):e21-24.

49. Hervier B, Arnaud L, Charlotte F, Wechsler B, Piette JC, Amoura Z, Haroche J. Treatment of Erdheim-Chester disease with long-term high-dose interferon-alpha. Semin Arthritis Rheum. 2012;41(6):907-913. 